\title{
Dynamics of Income Distribution
}

\author{
by \\ Hongyi $\mathrm{Li}$ \\ Chinese University of Hong Kong \\ Danyang Xie \\ Hong Kong University of Science \& Technology \\ and \\ Heng-fu Zou ${ }^{1}$ \\ Development Research Group, The World Bank
}

Revised $^{2}$ : July 1999

\begin{abstract}
In this paper, we have obtained closed-form solutions in Cass-Koopmans growth models with heterogeneous agents. The relationship between the form of production function and the dynamics of income distribution is made explicit. We then use this relationship to determine what production structure is simultaneously consistent with facts on growth and income inequality. Our empirical findings give support to models with decreasing returns in the reproducible factor.
\end{abstract}

Key Words: Income Distribution; Economic Growth.

JEL\#: D3, O1, O4.

\footnotetext{
${ }^{1}$ Mailing Address: Dr. Heng-fu Zou, World Bank, MC2-611, 1818 H St. NW, Washington, DC 20433, USA

${ }^{2}$ We would like to thank two anonymous referees for their very helpful comments.
} 


\section{Introduction}

A typical feature of endogenous growth models is that the production structure exhibits linearity in a reproducible factor. In Romer (1986), the reproducible factor is knowledge; in Lucas (1988), it is human capital; whereas in Rebelo (1991), it is a composite capital stock. Even in the models emphasizing technological change such as Romer (1990), Grossman and Helpman (1991a, 1991b), and Aghion and Howitt (1992), the linearity assumption exists in the R\&D sector.

The validity of this linearity feature is examined in a number of empirical work. Barro and Sala-i-Martin (1992) finds that the 'AK'-type models are inconsistent with the empirical evidence on convergence. Jones (1995a) and Kocherlakota and Yi (1996) test the persistence of policy shocks on economic growth and obtain contradictory results: the latter supports the endogenous growth framework whereas the former rejects it and advocates instead a semiendogenous growth framework described in Jones (1995b). In this paper, we would like to test the endogenous growth theory by exploring its implications on the dynamics of income distribution.

Prominent recent examples of theoretical and empirical studies on income distribution include Lucas (1992), Atkeson and Lucas (1992), Alesina and Rodrik (1994), and Persson and Tabellini (1994). Our paper, however, is more closely related to Chatterjee (1994) and Caselli and Ventura (1996). In essence, our model is a special case of these two studies. Chatterjee (1994) analyses the transitional dynamics and the distribution of wealth in a neoclassical growth model. In particular, he focuses on how the form of utility function may affect the results. Caselli and Ventura (1996) is much more general and rigorous but again with a focus different from ours. They first demonstrate that income distribution can display any dynamic pattern once the utility function is not confined to the special classes studied in Chatterjee (1994). Then, using a U.S. panel data set which reports income at the family level, they find that there has been a reversal in distributive dynamics during the 1970-1990 period. They argue that this reversal, albeit consistent 
with broad consumer preferences, casts doubt on the simple framework of logarithmic utility function and the Cobb-Douglas technology.

None of these two studies, however, sheds any light on the debate raised at the beginning. The criticism on the endogenous growth theory so far is not on the form of utility function used. Typically, a CES utlity function with zero subsistence consumption level is assumed. The criticism is on the production structure, which we investigate here. In this respect, we differ from Chatterjee (1994) and Caselli and Ventura (1996). More importantly, we obtain closed-form solutions that make the analysis more easily accessible.

We show explicitly in a set of examples that if the initial capital stock in an economy is less than the golden-rule capital stock, wealth will become more evenly distributed over time when the technology exhibits decreasing returns in the reproducible factor. The income distribution is time-invariant when the technology is linear in the reproducible factor. This implication is then tested empirically.

In our empirical test, we use a newly compiled cross-country panel data from the World Bank by Deininger and Squire (1996). We show that as an economy grows, income distribution does improve. This holds even when we explicitly control for government spendings (on education, welfare, social security, health and infrastructure) that are supposed to lower income inequalities. This empirical finding therefore gives support to models with decreasing returns in the reproducible factor.

The rest of the paper is organized as follows. Section 2 describes the standard CassKoopmans model with heterogeneous individuals. In section 3, we present a version of an endogenous growth model and study its implications for the dynamics of income distribution. Section 4 presents an empirical test of the implications, and Section 5 concludes. 


\section{An Extended Cass-Koopmans Model}

We consider an economy with a single consumption good and an infinite number of longlived agents situated in the real interval $[0,1]$. These agents are indexed by $i, i \in[0,1]$. The preferences of agent $i$ are given by

$$
\int_{0}^{\infty}\left[\frac{c_{i}^{1-\sigma}-1}{1-\sigma}\right] e^{-\rho t} d t
$$

where $c_{i}$ is individual $i$ 's consumption of the single good, $\sigma$ is the inverse of the intertemporal elasticity of substitution, and $\rho$ is the rate of time preference.

Let $a_{i}$ denote the amount of asset that individual $i$ holds. We normalize the time so that each individual has one unit of labor to supply and the supply is inelastic. The accumulation of the asset is thus as follows:

$$
\dot{a}_{i}=r a_{i}+w-c_{i} \text { with } a_{i}(0) \text { given, }
$$

where $r$ is the market real interest rate and $w$ the real wage.

Consumer $i$ 's decision on consumption and saving can be obtained from maximizing (1) subject to (2). The first-order condition is familiar:

$$
\frac{\dot{c}_{i}}{c_{i}}=\frac{r-\rho}{\sigma}
$$

and the transversality condition for optimality is as usual: $c_{i}^{-\sigma} a_{i} e^{-\rho t} \rightarrow 0$.

We assume that there are an infinite number of identical competitive firms, indexed by $j, j \in[0,1]$. The production function of firm $j$ is

$$
y_{j}=A K_{j}^{\alpha} L_{j}^{1-\alpha}
$$

where $K_{j}$ is the capital input and $L_{j}$ is the labor input. Parameter $A$ measures the total factor productivity and $\alpha$ is in $(0,1)$. These competitive firms take the real interest rate $r$ and the real wage $w$ as given. The usual profit maximizing conditions for these firms are: 


$$
\begin{gathered}
r=\alpha A K_{j}^{\alpha-1} L_{j}^{1-\alpha} \\
w=(1-\alpha) A K_{j}^{\alpha} L_{j}^{-\alpha}
\end{gathered}
$$

Since these firms are assumed to be identical, we have $K_{j} \equiv K$, and $L_{j} \equiv L$ for any $j$.

In equilibrium, demand equals supply. In particular, the aggregate demand for capital $K$ equals the aggregate supply of funds available, $\int_{0}^{1} a_{i} d i$; and the aggregate demand for labor $L$ equals the aggregate supply of labor, which is unity ${ }^{3}$.

The question we want to study is: How will income distribution evolve over time if individuals' initial asset holdings $a_{i}(0), i \in[0,1]$ are different from each other? Will income distribution become more equitable?

Even in this simple model, the answer can not be obtained directly. The difficulty is due to two reasons. First, there is heterogeneity in agents. Second, the real interest rate $r$ and the real wage $w$ can change over time as the aggregate capital stock increases or decreases. Chatterjee (1994) shows that for some classes of utility functions, which include the ones we study here, income distribution will be more equitable as time evolves if the economy starts with a capital stock lower than the golden rule. Caselli and Ventura (1996) show that with more general preferences, income distribution can display any dynamic pattern. The mathematical proofs in these two papers are done skillfully but most readers will have problems digesting them. In this paper, we will use a few examples in which closed form solutions exist so that readers may have a clearer picture of how income distribution evolves over time. To obtain closed form solutions, we need to impose a constraint on the parameters across the utility function and the production function, namely $\sigma=\alpha$. This is the same constraint imposed in Xie (1991, 1994), and Devarajan, Xie and Zou (1998). By doing this, we are not claiming that in reality $\sigma$ and $\alpha$ are the same. The 
objective here is purely technical: imposing $\sigma=\alpha$ greatly simplifies the dynamics and makes qualitative results readily accessible. This approach complements the rigorous analysis in Chatterjee (1994) and Caselli and Ventura (1996) in a useful way: it allows us to obtain an insight as to how the form of the aggregate production function may affect the dynamics of income distribution.

The equations that govern the evolution of an individual's asset can be summarized as follows.

$$
\begin{gathered}
\dot{a}_{i}=\alpha A K^{\alpha-1} a_{i}+(1-\alpha) A K^{\alpha}-c_{i} \\
\frac{\dot{c}_{i}}{c_{i}}=\frac{\alpha A K^{\alpha-1}-\rho}{\sigma} .
\end{gathered}
$$

Note that in the above equations, the real interest rate and the real wage have been substituted in by their expressions in equations (5) and (6). Given the initial asset $a_{i}(0)$ and the transversality condition, we can solve in principle for $a_{i}$ once the aggregate capital stock is known. Therefore, what we need to find out is the evolution of the aggregate capital stock.

$$
\begin{aligned}
& \text { Since } K=\int_{0}^{1} a_{i} d i \text {, we have: } \\
& \qquad \begin{aligned}
\dot{K} & =\alpha A K^{\alpha-1} \int_{0}^{1} a_{i} d i+(1-\alpha) A K^{\alpha}-\int_{0}^{1} c_{i} d i \\
& =A K^{\alpha}-C
\end{aligned}
\end{aligned}
$$

where $C=\int_{0}^{1} c_{i} d i$ is the aggregate consumption. From equation (8), we see that the growth rate of $c_{i}$ is independent of $i$. As a result, we have

$$
\frac{\dot{C}}{C}=\frac{\alpha A K^{\alpha-1}-\rho}{\sigma}
$$

\footnotetext{
${ }^{3}$ Since the firms are identical and are assumed to be situated in the interval [0,1], it follows that the aggregate demand for capital is the same as the average demand for capital. Similarly, since individuals fill the interval $[0,1]$, the aggregate supply of labor equals the average supply of labor, which is unity.
} 
Equations (9) and (10) normally do not lead to an explicit optimal consumption rule, but they do when the assumption $\alpha=\sigma$ is made. In fact, when $\alpha=\sigma$, the two equations above yield

$$
\frac{\dot{C}}{C}-\frac{\dot{K}}{K}=\frac{C}{K}-\frac{\rho}{\alpha}
$$

which has an obvious solution $C / K=\rho / \alpha$. Other solutions to (11) are invalid because they are not consistent with individual $i$ 's optimization behavior that requires the transversality condition to be satisfied. $C=\rho K / \alpha$ is thus the only optimal consumption rule in the aggregate sense. Therefore, the evolution of aggregate capital stock is much simplified:

$$
\dot{K}=A K^{\alpha}-\rho K / \alpha, \text { with } K(0)=\int_{0}^{1} a_{i}(0) d i
$$

Define $\phi_{i}=c_{i} / C$. From equation (8) and (10), we notice that $\phi_{i}$ is constant over time although it may be different for a different $i$. For the evolution of individual's asset, we have the following theorem.

Theorem 1. The asset holding of individual $i$ at time $t$ is given by

$$
a_{i}(t)=\phi_{i} K+(1-\alpha) A\left(\phi_{i}-1\right) K^{\alpha} / \rho
$$

where $\phi_{i}$ is given by

$$
\phi_{i}=\frac{\rho a_{i}(0)+(1-\alpha) A K(0)^{\alpha}}{\rho K(0)+(1-\alpha) A K(0)^{\alpha}}
$$

Proof. Obviously $c_{i}$ satisfies equation (8) because it is a constant factor of $C$. There are two things we need to verify. First, given $K$ satisfying equation (12), $a_{i}$ thus determined in (13) satisfies equation (7). This is straightforward and is checked. Second, we need to show that $a_{i}$ and $c_{i}$ satisfy the transversality condition $c_{i}^{-\sigma} a_{i} e^{-\rho t} \rightarrow 0$. Note that equation (12) indicates that $K$ will converge to a steady state $K^{*}$, where $K^{*}=[A \alpha / \rho]^{1 /(1-\alpha)}$. Thus, $C$ will converge to 
$\rho K^{*} / \alpha$. As a result, $c_{i}$ and $a_{i}$ will also converge to their steady state values. The transversality condition is thus satisfied.

REMARK: The result here is rather intuitive. Obviously $\phi_{i}$ should depend on individual $i$ 's initial asset holding relative to the initial aggregate (the average) capital stock. Equation (14) says that $\phi_{i}$ will be greater (smaller) than unity if individual $i$ is initially richer (poorer) than the average. As a result, when individual $i$ is richer than the average, $a_{i}$ is a concave function of $K$. When individual $i$ is poorer than the average, $a_{i}$ is a convex function of $K$. This remark leads to the following corollary (see Figure 1 for illustration).

Corollary: If $K(0)<K^{*}$, then income distribution improves over time. If $K(0)>K^{*}$, income distribution worsens over time.

As we believe that no country has passed the golden rule steady state yet, the above corollary states that we should expect the income distribution to get better with income growth. This conclusion however may break down, as we will see in the next section, if endogenous growth is allowed.

\section{A Model of Endogenous Growth}

We now introduce positive externality in goods production to generate long run growth as in Romer (1986) and Lucas (1988). The version presented here is adopted from Xie (1991). Specifically, the production function of the competitive firm $j$ is extended to include an externality term:

$$
y_{j}=A K_{j}^{\alpha} L_{j}^{1-\alpha} \Gamma(K)
$$

where $K$ denotes the aggregate capital stock as before. $\Gamma(K)$ is an increasing function of $K$, meaning that as the aggregate capital increases, the productivity of capital and labor employed in 
firm $j$ becomes higher. In this case, the real interest rate and the real wage can be calculated as follows.

$$
\begin{gathered}
r=\alpha A K_{j}^{\alpha-1} L_{j}^{1-\alpha} \Gamma(K) \\
w=(1-\alpha) A K_{j}^{\alpha} L_{j}^{-\alpha} \Gamma(K) .
\end{gathered}
$$

In equilibrium, we still have $K_{j} \equiv K$, and $L_{j} \equiv 1$. Thus the evolution of $K$ is determined

by

$$
\begin{aligned}
\dot{K} & =\alpha A K^{\alpha-1} \Gamma(K) K+(1-\alpha) A K^{\alpha} \Gamma(K)-C \\
& =A K^{a} \Gamma(K)-C
\end{aligned}
$$

The equations that determine individual's asset accumulation are thus as follows.

$$
\begin{gathered}
\dot{a}_{i}=\alpha A K^{\alpha-1} \Gamma(K) a_{i}+(1-\alpha) A K^{\alpha} \Gamma(K)-c_{i} \\
\frac{\dot{c}_{i}}{c_{i}}=\frac{\alpha A K^{\alpha-1} \Gamma(K)-\rho}{\sigma} .
\end{gathered}
$$

Again, from (20), we see that

$$
\frac{\dot{C}}{C}=\frac{\alpha A K^{\alpha-1} \Gamma(K)-\rho}{\sigma} .
$$

Unfortunately, these equations are not easy to solve for arbitrary function of $\Gamma(K)$, even if we impose the assumption $\alpha=\sigma$. Numerical methods are therefore needed to reach any reliable conclusions. But before we call in the researchers equipped with numerical techniques, we want to see whether we can make some intelligent qualitative conjectures about how income distribution evolves as economy moves on.

To this end, let us look at one special functional form of $\Gamma(K)$, namely, $\Gamma(K)=K^{1-\alpha}$. In this case, the real interest rate is constant, $r=\alpha A$. Thus, the growth rate of consumption for all individuals are constant over time, so is the aggregate consumption. And the evolutions of aggregate capital and individual $i$ 's asset are as follows.

$$
\dot{K}=A K-C
$$




$$
\dot{a}_{i}=\alpha A a_{i}+(1-\alpha) A K-c_{i} .
$$

The solution now is obvious. That is,

$$
\begin{gathered}
K=K(0) e^{(\alpha A-\rho) t / \sigma} \\
a_{i}=a_{i}(0) e^{(\alpha A-\rho) t / \sigma} .
\end{gathered}
$$

In other words, $a_{i}$ is always proportional to $K$. As a result, income distribution stays the same over time (see Figure 2 for illustration).

Let us summarize what we have obtained thus far. The example in the last section corresponds to the case where $\Gamma(K) \equiv 1$. There, we find that the optimal trajectory is concave for $a_{i}(0)>K(0)$ and convex for $a_{i}(0)<K(0)$. In the case when $\Gamma(K) \equiv K^{1-\alpha}$, the optimal trajectory is linear for any $a_{i}(0)$. In both examples, these optimal trajectories can be extended back to the origin. If we look at these two examples closely, we find that the first example has the property that the aggregate production is concave in $K$, and in the second example the aggregate production function is linear in $K$. Based on this observation, we have the following conjecture.

Conjecture: If $\Gamma(K)$ is such that the aggregate production function $A K^{\alpha} \Gamma(K)$ is concave, then the optimal trajectory is concave for $a_{i}(0)>K(0)$ and convex for $a_{i}(0)<K(0)$. If the aggregate production function $A K^{\alpha} \Gamma(K)$ is convex ${ }^{4}$, then the optimal trajectory is convex for $a_{i}(0)>K(0)$ and concave for $a_{i}(0)<K(0)$.

If our conjecture is right, then when the aggregate production function $A K^{\alpha} \Gamma(K)$ is convex, income distribution gets worse as the economy moves forward.

\footnotetext{
4 To make sure that the optimization problem is well-defined, we need to assume that $\lim _{K \rightarrow \infty} A K^{\alpha} \Gamma(K)<\rho /(1-\sigma)$
} 


\section{Empirical Testing}

In our theoretical discussions above, we find that whether income distribution will improve over time depends on the strict concavity of technology. In principle, we can examine the empirical evidence on the dynamics of income distribution to determine whether the existing linearity feature assumed in the Endogenous Growth literature is valid or not. Given the fact that for any particular country, time series data on income distribution (the Gini coefficient) is available for only scattered periods, we have to enlarge the sample by pooling countries together. We then run a regression of Gini against income level to see if income distribution improves as an economy expands. If the answer is positive, then the production structure should exhibit decreasing returns in the reproducible factor rather than constant or increasing returns. Of course, we need to control for other obvious variables which affect income distribution, namely government spending and taxes. To this end, let us first describe the newly compiled data set on income distribution.

\subsection{Data description}

Many existing empirical studies have been hampered by the data problems on income distribution. The commonly available data sets have used very different definitions of the Gini coefficients and covered very few observations over time and across countries. In our study, the data on income distribution (the Gini coefficients) are taken from the Deininger and Squire $(1996)^{5}$. This is a newly compiled and greatly expanded data set on income distribution. To minimize the methodological differences in defining the Gini coefficients, only the Gini coefficients from national coverage household survey based on gross income, net income or expenditure are selected. Thus the consistency of the definition of the Gini coefficients is well

\footnotetext{
${ }^{5}$ We have utilized the new data set to study other dynamic issues related to income distribution; see Li and Zou (1998); and Li, Squire and Zou (1998).
} 
maintained. We found that in our sample, it is statistically significant that the Gini coefficients based on gross income is 4.0 higher than those based on net income or expenditure, while other differences in definitions such as household vs. personal income, do not have statistically significant impact on the Gini measurement. Thus, if the Gini coefficient is 35 based on gross income, then the definition-adjusted Gini coefficient is 31 , which is comparable to the Gini coefficient based on net income or expenditure. Therefore, the Gini coefficient data used in our analysis can be regarded as the after-tax measurement of income inequality.

The current sample of the Gini coefficients (after adjusting for difference in definitions, denoted as GINI) consists of 84 countries with a total of 583 observations for a time period from 1950 to 1992 . Among the 84 countries, 37 have less than or equal to 3 observations; 30 have between 4 to 9 observations; 11 have between 10 to 20 observations; and six have more than 20 observations. This is a highly unbalanced panel data set of income inequality. See Table 1 for the summary statistics of GINI by individual countries. The maximum value of GINI is 58.6 for Gabon, the minimum value of GINI is 16.81 for Bulgaria.

Table 3 reports the summary statistics of GINI by different samples. The overall mean and standard deviation are 34.66 and 8.63 , respectively. We further divide the overall sample into high-income sample and middle- and low-income sample according to the classification of the World Development Report by the World Bank. There are 24 high-income countries and 60 middle- and low-income countries. The high-income countries are more equal in income distribution in the sense that the mean of GINI is 30.94 (standard deviation 4.36) compared to 38.14 (Standard deviation 10.07) for the middle- and low-income sample, although for some of the (former) socialist countries in the middle- and low-income sample the Gini coefficients are low.

The income level data (real per capita GDP in constant dollars expressed in international prices, Y), is taken from Summers and Heston (1995) where it is denoted as $R G D P C H$ there. Since for most countries, the coverage of the Gini coefficients determines the number of valid 
observations in our sample, we only report results with respect to the sample where a match with the Gini data is found. Thus the complete sample includes 84 countries with 583 observations. For a summary statistics of the income level data $Y$ by individual countries, please refer to Table 2. The maximum is $\$ 18,095$ for the US, the minimum is $\$ 419$ for Tanzania. The overall mean and standard deviations are $\$ 6,435$ and $\$ 4,655$, respectively. Finally, the summary statistics of $Y$ by subsamples are reported in Table 3. Note that the high-income sample has low mean Gini while the middle- and low-income sample has high mean Gini. Therefore income level and Gini are in general negatively correlated.

\subsection{Theoretical predictions and regression estimation results}

The purpose of the empirical analysis is to see what production structure is consistent with facts on growth and income inequality. In particular, if we find that income distribution gets more even as income increases, then our theoretical sections argue that the production function should exhibit decreasing returns in the reproducible factor. In this case, the empirical evidence would cast doubt on the endogenous growth theories which rely on linearity or convexity in factors such as knowledge, human capital and physical capital.

What we are interested in is the sign of the coefficient in a regression of Gini against income level. As we said earlier, we probably need to control for taxation and government spending. Since taxation and government spending are highly correlated, we only include one of them in the regression. When taxation is included, the estimated coefficient on taxation is negative and statistically significant ${ }^{6}$ as expected. The coefficients on $Y$ are all negative but mostly insignificant. This is probably due to a $35 \%$ loss of observations because some countries do not have taxation data during early periods. Government spending data, however, are rather

\footnotetext{
${ }^{6}$ The statistical test of the significance of the regression coefficients is based on a $5 \% t$-test. This is the same for the other discussions if not otherwise specified.
} 
complete and using this variable does not lead to any severe loss of observations. Therefore, let us focus on the following regression ${ }^{7}$ :

$$
G I N I_{i t}=\alpha_{i}+\beta_{i} Y_{i t}+\eta_{i} G_{i t}+u_{i t}
$$

where $i$ is the country index $(i=1,2, \ldots, N), t$ is the time index $(t=1,2, \ldots, T)$, and $u_{i t}$ are $i i d$ errors. The dependent variable GINI is the Gini coefficients adjusted for differences in definitions, the independent variables are the real per capita income, $Y$, and the government spending, $G$. $G$ represents the government spending as a share of GDP and is taken from Summers and Heston (1995). On the basis of our theoretical model, we expect $\beta_{i}$ to be negative if a concave technology prevails and to be positive if a convex technology prevails. $\eta_{i}$ should be negative because theoretically government spending improves income distribution.

For the empirical estimation, we consider both the fixed-effects and the error components model specifications. For the fixed-effects model, we test for the equality of dummy coefficients. For the error components model two specification tests are conducted, the Lagrangian Multiplier test and the Hausman (1978) test. The Lagrangian Multiplier test is a $\chi^{2}(1)$-test for error components, with the null

$$
H_{0} \text { : Individual error components do not exist. }
$$

The Hausman test is a $\chi^{2}(k)$-test for error components, with the null

$$
H_{0} \text { : Error components model is the correct specification }
$$

where $k$ is the number of regressors in the regression. ${ }^{8}$ In general, our empirical results show that all the specification tests for the fixed-effects model or error components model do not justify the use of a simple pooled regression. Thus the pooled regression results are not reported.

\footnotetext{
7 We also considered a simpler version of regression (26), GINI $I_{i t}=\alpha_{i}+\beta_{i} Y_{i t}+u_{i t}$. The estimated regression coefficients and their statistical significance for $Y$ are very close to those of regression (26), therefore the results are not reported. They are available upon request.

${ }^{8}$ Since the Gini data for individual countries are in general time series with many missing observations, we will not further pursue using various specification tests for serial correlation and causality, or using lagged variables as instruments to account for possible endogeneity.
} 
Table 4 reports the estimation results of regression (26). Since government spending (on education, welfare, social security, health and infrastructure, etc.) often intends to provide a more equitable distribution for the society, it is expected to reduce the degree of income inequality. Indeed, that is what we found in the estimation results. Government spending has coefficients that are negative and significant in most of the cases. ${ }^{9}$

Our main interest is on the sign of coefficient on the income level. Table 4 reports that the coefficients of $Y$ are negative and significant for the middle- and low-income sample. For the high-income sample, they are negative, although insignificant. When using the complete sample, the coefficients are negative, but only significant for the error components (EC) model. We interpret this regression result as a support of production structure that exhibits strict decreasing returns in the reproducible factor. Therefore, our study on the dynamics of income distribution complements the work of Barro and Sala-i-Martin (1992) and Jones (1995a) that question the validity of the endogenous growth framework.

\subsection{The Kuznets hypothesis}

A study on income distribution will be incomplete if the issue of the Kuznets hypothesis is not addressed. Since existing empirical findings give contradictory results, it would be interesting to know whether our new data set supports the Kuznets hypothesis.

We directly test the Kuznets hypothesis between inequality and the level of income by considering the following regression:

$$
G I N I_{i t}=\alpha_{i}+\beta_{i} Y_{i t}+\gamma_{i}\left(Y_{i t}\right)^{2}+u_{i t}
$$

The Kuznets hypothesis suggests that inequality is low at lower income level but later increases at higher income level with economic growth. As the income level further grows, inequality

\footnotetext{
${ }^{9}$ This is also true for most of the cases in Table 5 where we test the Kuznets hypothesis and in Tables 6 and 7 where we perform the sensitivity analysis.
} 
decreases. Thus the relationship between income distribution and income level can be described by an inverted $U$-curve. Empirically this can be verified if the coefficient of $Y^{2}$ is negative.

The literature on Kuznets hypothesis is extensive, including both theoretical foundations and empirical studies. For example, see Adelman and Robinson (1989), Lindert and Williamson (1985) and Kaelble and Thomas (1991). Papanek and Kyn (1986) found that the relationship between income distribution and development is stable and robust to the inclusion of extra variables capable of capturing the differences in policy choices. Note that Papanek and Kyn (1986) consider a panel of 83 countries with only 145 observations over 1952-1978, while our data set has 84 countries with 583 observations covering 1950-1992. Ram (1991) investigates the Kuznets hypothesis using post-war US data on income distribution and does not find evidence supporting the Kuznets hypothesis. Kaelble and Thomas (1991) compare different empirical studies of the Kuznets hypothesis. While most of the previous empirical results concentrate on cross-country studies, we are able to explore the relationship between income distribution and income level using the newly compiled time-series cross-sectional data.

The results in Panel 1 of Table 5 show that the coefficients for $Y$ are all negative in all six cases, although not significant for the middle- and low-income sample. The coefficients for $Y^{2}$ are positive and significant for the high-income sample, but negative and insignificant for the middle- and low-income sample. For the complete sample, a regular $U$-curve is found. Therefore, there is only weak evidence supporting the Kuznets hypothesis for the middle- and low-income sample.

We also consider controlling for the effects of government spending when testing the Kuznets hypothesis in regression (30)

$$
G I N I_{i t}=\alpha_{i}+\beta_{i} Y_{i t}+\gamma_{i}\left(Y_{i t}\right)^{2}+\tau_{i} G_{i t}+u_{i t} .
$$


The results are reported in Panel 2 of Table 5. The coefficients of $Y$ and $Y^{2}$ and their statistical significance do not seem to change much when compared to those in Panel 1 for regression (29). The coefficients of government spending, $G$, on the other hand, are all negative and significant.

Different functional forms are often used when testing the Kuznets hypothesis. The most commonly used is the semi-log functional form. We reestimate regressions (29) and (30) using the natural logarithm of $Y$ to see whether the results for regressions (29) and (30) are subject to function form changes

$$
\begin{gathered}
G I N I_{i t}=\alpha_{i}+\beta_{i} \ln Y_{i t}+\gamma_{i}\left(\ln Y_{i t}\right)^{2}+u_{i t} \\
G I N I_{i t}=\alpha_{i}+\beta_{i} \ln Y_{i t}+\gamma_{i}\left(\ln Y_{i t}\right)^{2}+\tau_{i} G_{i t}+u_{i t}
\end{gathered}
$$

For regression (31), a regular $U$-curve is found for the complete sample, however, the coefficients are insignificant. When considering the subsamples, the high-income sample has a regular $U$ curve with significant coefficients. But an inverted $U$-curve for the middle- and low-income sample is found, again with insignificant coefficients. For regression (32), a regular $U$-curve for the high-income sample is found. On the other hand, an inverted $U$-curve for the middle- and low-income sample is found. All the coefficients are significant for $\ln Y$ and $(\ln Y)^{2}$ in the two cases. For the complete sample, the coefficients of $\ln Y$ and $(\ln Y)^{2}$ are insignificant. Finally, the coefficients of government spending are all negative and significant in all cases. The results are similar to those reported in Table 5 and therefore not reported. The only difference worth noting is that a statistically significant inverted $U$-curve relationship is found for the middle- and lowincome sample.

\subsection{Sensitivity analysis}

In this section, we perform a sensitivity analysis to test the robustness of the results reported in the earlier sections. For a description of the methodology used here, see Levine and Renelt (1992). The essential idea is to see whether the regression results are sensitive to the 
inclusion of other related regressors. We add a list of extra variables into the regressions (defined as base regressions) discussed in the earlier sections to test the robustness of the estimation results of our main interest. The list of extra variables includes PGRW, OPEN, FNDP and TOTSK (to be explained below). ${ }^{10}$ The base regressions are reestimated each time three different variables taken from the extra variable list are added.

The variable openness $(O P E N)$ is taken from Summers and Heston (1995). The openness is measured as the total trade value (imports + exports) over GDP. Other variables such as population growth $(P G R W)$, financial development $(F N D P)$ (measured as $M 2 / G D P)$ and termsof-trade shocks (TOTSK, defined as $\left(\Delta \ln P_{X}-\Delta \ln P_{M}\right)$, where $P_{X}$ and $P_{M}$ are export unit price and import unit price, respectively) are taken from the BESD (Bank Economic and Social Database) of the World Bank. For detailed sources of all the variables, see Table 8 (Data Appendix).

The regression results of the sensitivity analysis are reported in Table 6 for regression (26) and Table 7 for regressions (29) and (30). To save space, only results for the fixed-effects model are reported. For regression (26), we are interested in testing the robustness of the regression coefficients of $Y$ and $G$. For the middle- and low-income sample, the coefficients of $Y$ are all negative and significant. On the other hand, $G$ has in some cases positive but insignificant coefficients. For the high-income sample, the coefficients of $Y$ are all negative but insignificant. The regression coefficients of $G$ are mostly negative and significant. For the complete sample, some of the coefficients are insignificant, but the signs are all negative. It is not difficult to see that the coefficients are mostly robust to the theoretical predications and also consistent with the base regression coefficient estimates.

In the sensitivity analysis, a strong and positive statistical tie has been identified between financial depth and income distribution. Population growth seems to have a positive effect on

\footnotetext{
${ }^{10}$ One can consider a longer list of variables typically used in the growth literature, as done in Levine and
} 
reducing income inequality in middle- and low-income sample. For the high-income sample and the complete sample, population growth tends to increase income inequality. However, the relationship between population growth and income inequality is statistically weak in all cases.

Openness seems to be negatively related to income inequality for the high-income sample and vise versa for the middle- and low-income sample. On the other hand, the terms-of-trade shock has a positive relationship with GINI for the complete sample and the high-income sample, while for the middle- and low-income sample, the relationship is negative. For both variables, the relationship with GINI is not statistically significant.

For regressions (29) and (30) (the Kuznets hypothesis), in general, the sensitivity analysis supports a regularly shaped $U$-curve for the high-income sample with a strong statistical significance. However, an inverted $U$-curve is found for the middle- and low-income sample, although in most cases the coefficients on $Y$ and $Y^{2}$ are insignificant. For the complete sample, the results also indicate a regular shaped $U$-curve, similar to the high-income sample. See the results in Table 7. To summarize, the sensitivity analysis in general supports the results reported in the earlier sections.

\section{Conclusion}

In this paper, we provide a test on the validity of the linearity assumption in the endogenous growth models. Our test is performed on the implications of this assumption on the dynamics of income distribution, which we illustrate using a set of examples with closed-form solutions. In particular, we see that in the standard Cass-Koopmans model with a concave production function, income distribution improves if the initial capital stock in the economy is less than the golden rule steady state ${ }^{11}$. If the production function is linear in the reproducible

\footnotetext{
Renelt (1992). We use only a few important ones to highlight the main results.

${ }^{11}$ A similar result can be found in Stiglitz (1969). His result however is derived from an assumption on the saving function instead of one on preference structure.
} 
factor, income distribution is time-invariant ${ }^{12}$. With a convex production function, we conjecture that the income distribution worsens with income growth. Our empirical tests show that the income distribution tends to improve over time with income growth. Therefore, our study on the dynamics of income distribution supports the findings by Barro and Sala-i-Martin (1992) and Jones (1995a) that question the validity of the endogenous growth framework.

We have also obtained two empirical results that are of independent interests on the issue of income distribution. First, as expected, income taxation and government spending lower income inequalities. Second, the Kuznets hypothesis on income inequality does not hold for the new data set when the complete sample is used. However, there is some evidence that the Kuznets hypothesis holds for the middle- and low-income sample.

\footnotetext{
${ }^{12}$ Bertola (1993) and Krusell, Quadrini and Rios-Rull (1997) have similar results but they address issues different from ours.
} 


\section{References}

Adelman, Irma and Sherman Robinson, (1989), "Income Distribution and Development," in: Handbook of Development Economics, Vol. II, (eds.) H. Chenery and T.N. Srinivasan.

Aghion, Philippe, and Peter Howitt, (1992) "A Model of Growth through Creative Destruction," Econometrica, LX: 323-351.

Alesina, A. and D. Rodrik, (1994), "Distributive Politics and Economic Growth," The Quarterly Journal of Economics, May 465-490.

Atkeson Andrew and Robert E. Lucas, Jr., (1992), “On Efficient Distribution with Private Information," Review of Economic Studies 59:427-453.

Bertola, Giuseppe, (1993), "Factor Shares and Savings in Endogenous Growth," American Economic Review, Vol. 83: 1184-1198.

Caselli, Francesco and Jaume Ventura, (1996), "A Representative Consumer Theory of Distribution," Manuscript, Harvard University.

Chatterjee Satyajit (1994), "Transitional Dynamics and the Distribution of Wealth in a Neoclassical Growth Model,” Journal of Public Economics, Vol. 54: 97-119.

Deininger, Klaus, and Lyn Squire, (1996), “A New Data Base on Income Distribution," The World Bank Economic Review, vol. 10: 565-592.

Devarajan, Shantayanan, Danyang Xie, and Heng-fu Zou, (1998), "Should Public Capital Be Subsidized or Provided?” Journal of Monetary Economics 41:319-331.

Hausman, Jerry, (1978), “Specification Tests in Econometrics,” Econometrica, Vol. 46:12511271.

Jones, Charles, (1995a), “Time Series Tests of Endogenous Growth Models," Quarterly Journal of Economics, Vol. 110: 495-525.

Jones, Charles, (1995b), "R\&D-Based Models of Economic Growth," Journal of Political Economy, Vol. 103: 759-784.

Kaelble, Hartmut and Mark Thomas, (1991), "Introduction," in Y.S. Brenner, Hartmut Kaelble and Mark Thomas (eds.), Income Distribution in Historical Perspective, Cambridge and Paris: Cambridge University Press and Editions de la Maison des Sciences de l'Homme.

Krusell P., Quadrini, V., and J.-V. Rios-Rull, (1997), "Politico-economic Equilibrium and Economic Growth,” Journal of Economic Dynamics and Control, Vol. 21: 243-272.

Levine, Ross and David Renelt, (1992), “A Sensitivity Analysis of Cross-country Growth Regressions," American Economic Review, Vol. 82: 942-63.

Li, Hongyi, Lyn Squire, and Heng-fu Zou, (1998), "Explaining International and Intertemporal Variations in Income Inequality.” Economic Journal 108:26-43. 
Li, Hongyi, and Heng-fu Zou, (1998), "Income Inequality is not Harmful for Growth: Theory and Evidence," Review of Development Economics 2:318-334.

Lindert, Peter H. and Jeffrey G. Williamson, (1985), "Growth, Equality, and History," Explorations in Economic History, Vol.22: 341-377.

Lucas, Robert, (1988), "On the Mechanics of Economic Development," Journal of Monetary Economics, Vol.22:3-42.

Lucas, Robert, (1992), “On Efficiency and Distribution,” Economic Journal Vol. 102:233-247.

Papanek, Gustav F. and Oldrich Kyn, (1986), "The Effect on Income Distribution of Development, the Growth Rate and Economic Strategy," Journal of Development Economics, Vol.23: 55-65.

Persson, T. and G. Tabellini, (1994), "Is Inequality Harmful for Growth?" The American Economic Review, 84, 600-621.

Ram, Rati, (1991), “Kuznets's Inverted- $U$ Hypothesis: Evidence from a Highly Developed Country," Southern Economic Journal, Vol.57:1112-1123.

Rebelo, Sergio, (1991), "Long-run Policy Analysis and Long-run Growth," Journal of Political Economy, Vol. 99: 500-521.

Romer, Paul, (1986), "Increasing Returns and Long-Run Growth,” Journal of Political Economy, Vol.94: 1002-1037.

Stiglitz, J.E., (1969), "Distribution of Income and Wealth Among Individuals," Econometrica, Vol. 37:382-397.

Summers, R. and A. Heston, (1995), "Penn World Table (Mark 5.6)."

World Bank, Bank Economic and Social Database (BESD).

Xie, Danyang, (1991), "Increasing Returns and Increasing Rates of Growth," Journal of Political Economy, Vol. 99:429-435.

Xie, Danyang, (1994), "Divergence in Economic Performance: Transitional Dynamics with Multiple Equilibria," Journal of Economic Theory, Vol. 63:97-112. 
a

Individual's wealth

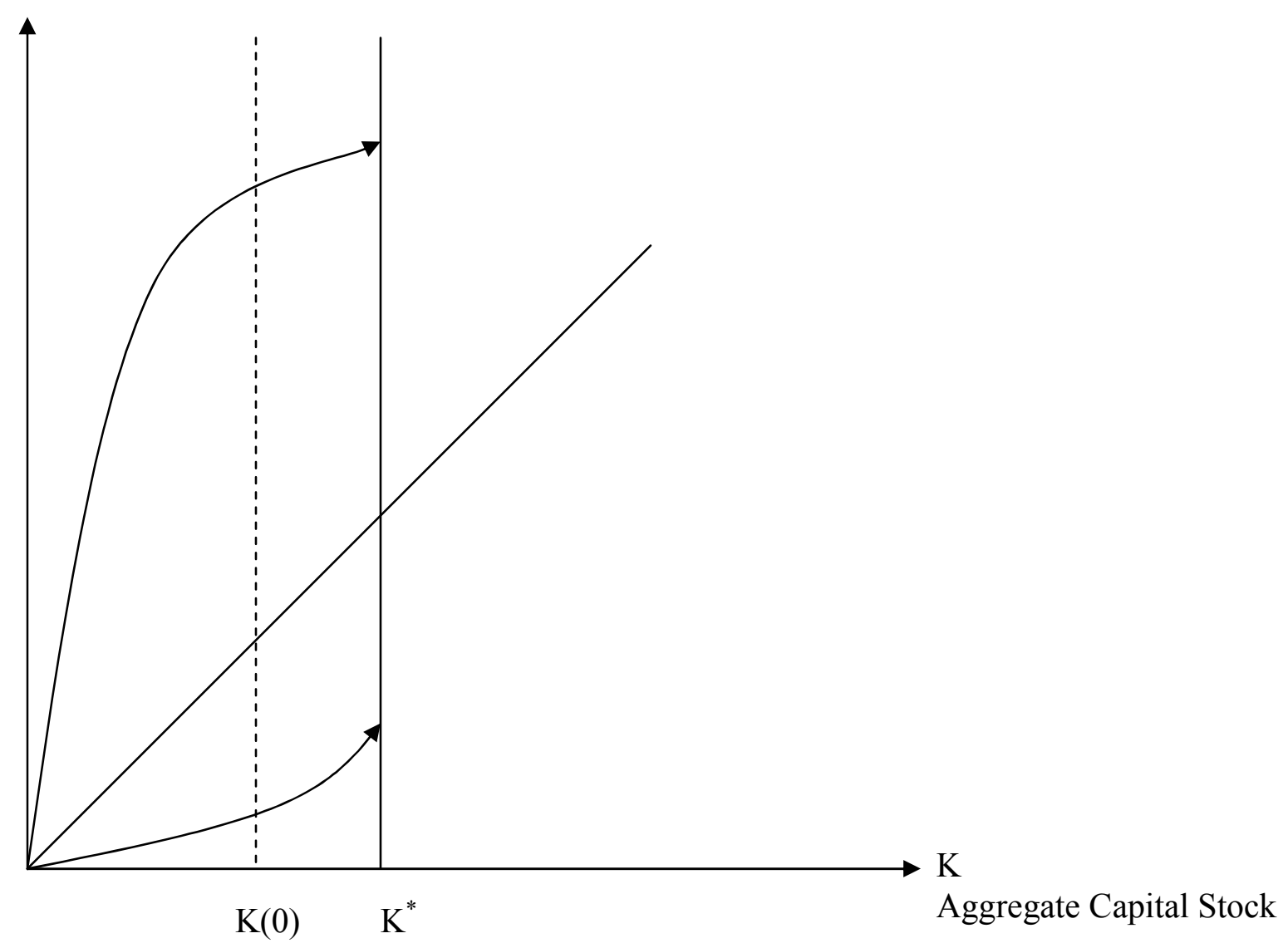

Figure 1: Standard Cass-Koopmans Model 
a

Individual's wealth

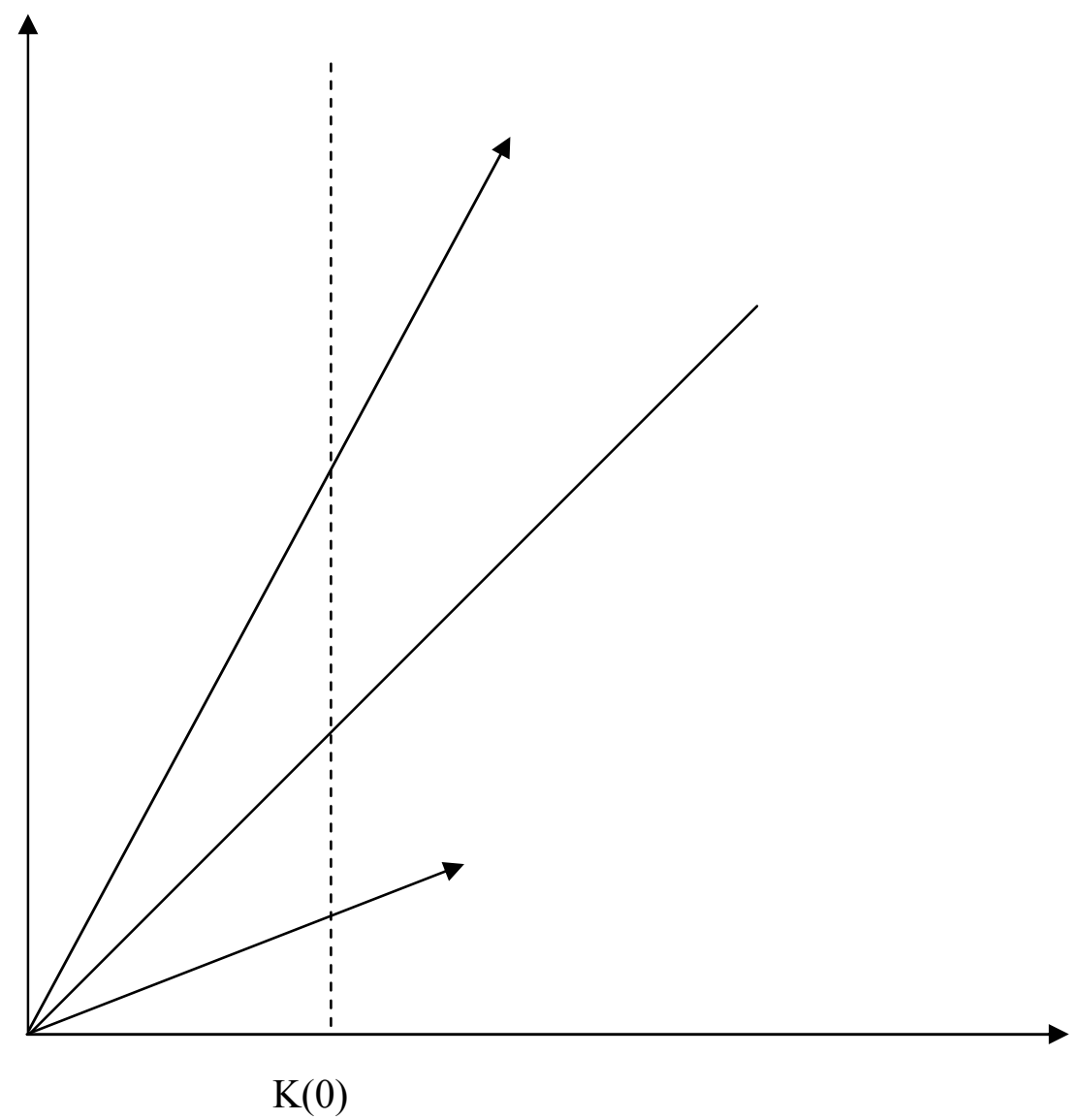

Figure 2: Endogenous Growth with a Linear Technology 


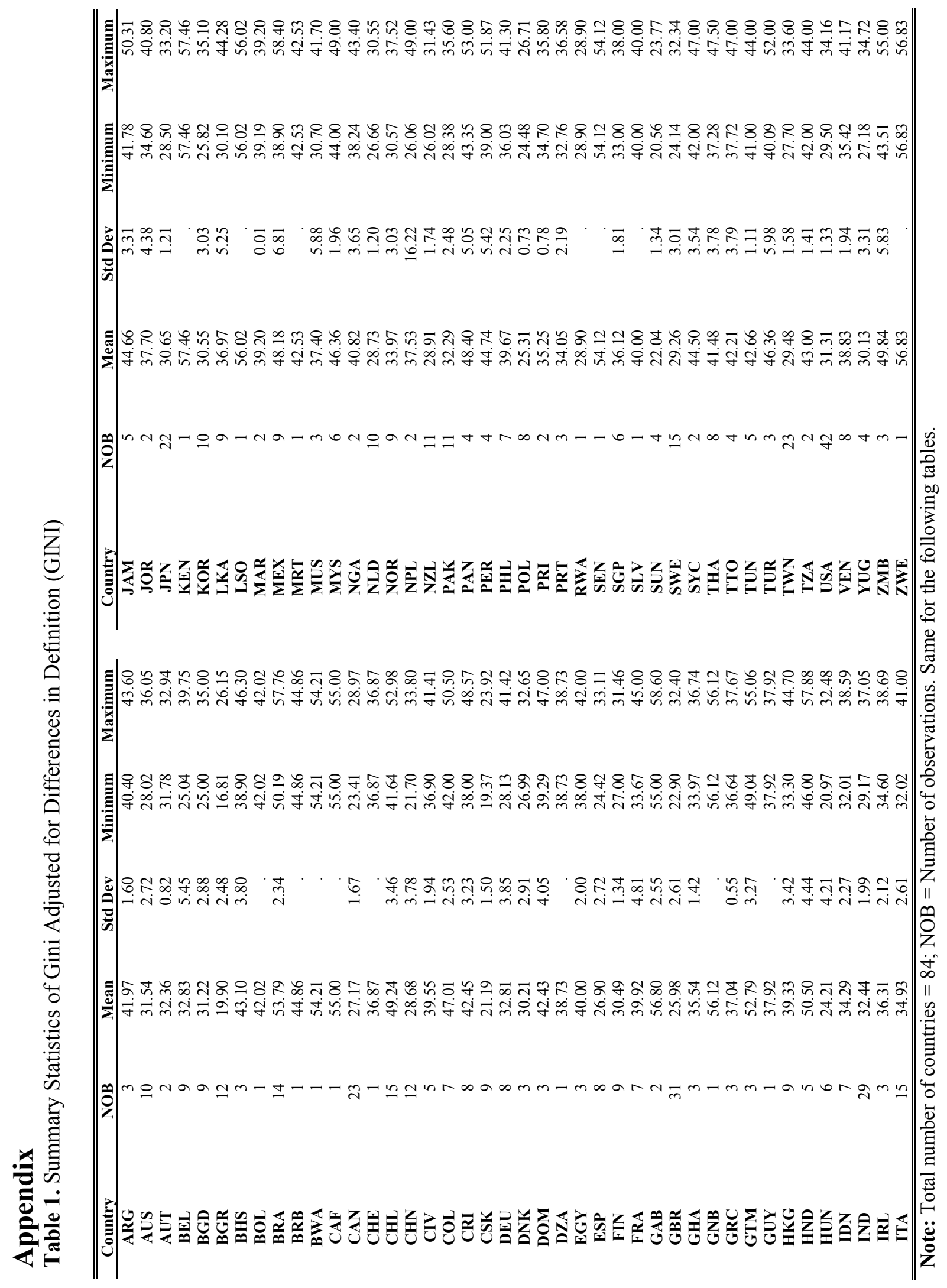




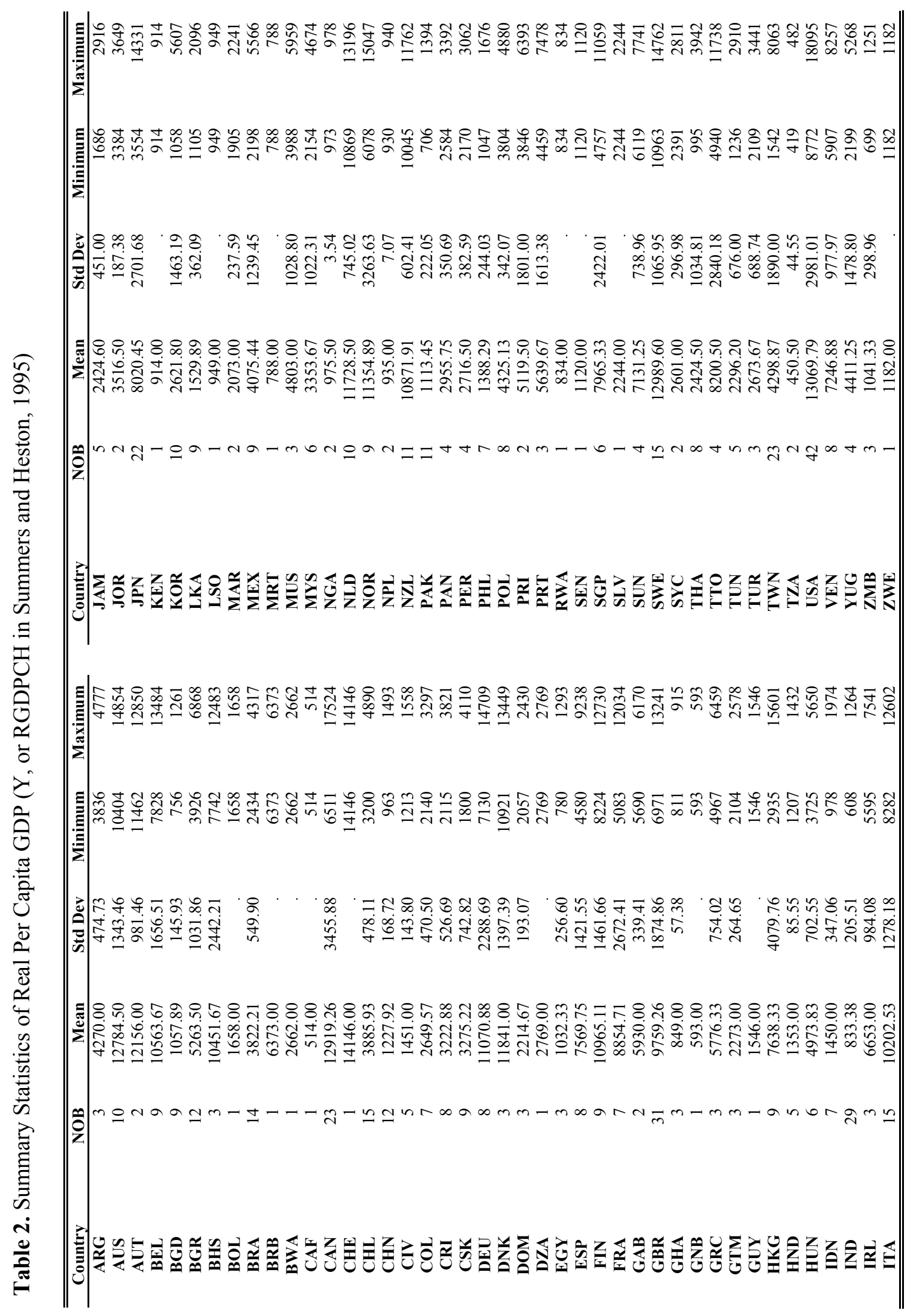


Table 3. Summary Statistics of GINI and Y by Income Groups

\begin{tabular}{clccccc}
\hline \hline Sample & NOB & Mean & Std Dev & Minimum & Maximum \\
\hline GINI & Overall (NOC = 84) & 583 & 34.66 & 8.63 & 16.81 & 58.6 \\
& $\begin{array}{l}\text { High-income (NOC = 24) } \\
\text { Middle- and Low-income } \\
\text { (NOC = 60) }\end{array}$ & 282 & 30.94 & 4.36 & 22.9 & 46.3 \\
\hline Y & 301 & 38.14 & 10.07 & 16.81 & 58.6 \\
\hline & Overall (NOC = 84) & 583 & 6435.15 & 4655.66 & 419 & 18095 \\
& $\begin{array}{l}\text { High-income (NOC = 24) } \\
\text { Middle- and Low-income } \\
\text { (NOC= 60) }\end{array}$ & 282 & 10293.48 & 3465.47 & 1542 & 18095 \\
\hline \hline
\end{tabular}

Note: Middle- and Low-income sample and High-income sample are defined according to the World Development Report classification.

Table 4. Estimation Results of Regression (26)

Dependent variable: GINI

\begin{tabular}{|c|c|c|c|c|c|c|}
\hline \multirow{2}{*}{$\begin{array}{c}\text { Sample } \\
\text { Model }\end{array}$} & \multicolumn{2}{|c|}{$\begin{array}{r}\text { Middle- and Low-income } \\
\text { Sample }\end{array}$} & \multicolumn{2}{|c|}{ High-Income Sample } & \multicolumn{2}{|c|}{ Complete Sample } \\
\hline & (1) $\mathrm{FE}$ & (2) $\mathrm{EC}$ & (3) $\mathrm{FE}$ & (4) EC & (5) $\mathrm{FE}$ & (6) EC \\
\hline \multirow[t]{2}{*}{ Constant } & -- & 45.20 & -- & 37.88 & -- & 41.58 \\
\hline & $(--)$ & (24.12) & $(--)$ & (21.12) & $(--)$ & $(28.96)$ \\
\hline \multirow[t]{2}{*}{$\mathbf{Y}$} & -0.70 & -0.83 & -0.04 & -0.05 & -0.09 & -0.17 \\
\hline & $(-2.40)$ & $(-3.15)$ & $(-0.64)$ & $(-0.77)$ & $(-1.28)$ & $(-2.43)$ \\
\hline \multirow[t]{2}{*}{ G } & -0.16 & -0.10 & -0.30 & -0.35 & -0.19 & -0.12 \\
\hline & $(-2.21)$ & $(-1.59)$ & $(-2.41)$ & $(-3.28)$ & $(-3.40)$ & $(-2.33)$ \\
\hline $\mathbf{R}^{2}$ & 0.91 & & 0.72 & & 0.90 & \\
\hline F-test & 42.05 & & 22.18 & & 47.06 & \\
\hline LM-test & & 6413.59 & & 1747.35 & & 10874.18 \\
\hline H-test & & 3.01 & & 0.99 & & 16.80 \\
\hline NOB & 301 & 301 & 282 & 282 & 583 & 583 \\
\hline NOC & 60 & 60 & 24 & 24 & 84 & 84 \\
\hline
\end{tabular}

Note: $\mathrm{FE}=$ Fixed-effects model; $\mathrm{EC}=$ Error-components model; $\mathrm{R}^{2}=\mathrm{R}^{2}$ for OLS dummy regression $(\mathrm{FE})$; F-test $=$ F-test for equality of dummy coefficients; LM-test $=$ Lagrange Multiplier test $\left(\chi^{2}(1)\right)$ for error components, with null being "individual error components do not exist"; H-test = Hausman (1978) $\chi^{2}$ specification test, with the null being "error components model is the correct specification". For the fixed-effects model, the dummy coefficients are not reported. Same for other tables. 
Table 5. Testing the Kuznets Hypothesis (Estimation results of regressions (29) and (30))

\section{Dependent variable: GINI}

Panel 1: Base specification

\begin{tabular}{|c|c|c|c|c|c|c|}
\hline \multirow{2}{*}{$\begin{array}{l}\text { Sample } \\
\text { Model }\end{array}$} & \multicolumn{2}{|c|}{$\begin{array}{r}\text { Middle- and Low-income } \\
\text { Sample }\end{array}$} & \multicolumn{2}{|c|}{ High-Income Sample } & \multicolumn{2}{|c|}{ Complete Sample } \\
\hline & (1) $\mathrm{FE}$ & (2) $\mathrm{EC}$ & (3) $\mathrm{FE}$ & (4) EC & (5) $\mathrm{FE}$ & (6) EC \\
\hline \multirow[t]{2}{*}{ Constant } & -- & 42.49 & -- & 37.54 & -- & 42.40 \\
\hline & $(--)$ & $(25.56)$ & $(--)$ & $(22.83)$ & $(--)$ & $(36.21)$ \\
\hline \multirow[t]{2}{*}{$\mathbf{Y}$} & -0.09 & -0.31 & -0.95 & -0.95 & -0.98 & -1.21 \\
\hline & $(-0.13)$ & $(-0.49)$ & $(-3.67)$ & $(-3.74)$ & $(-3.93)$ & $(-5.33)$ \\
\hline \multirow[t]{2}{*}{$\mathbf{Y}^{2}$} & -0.07 & -0.06 & 0.04 & 0.04 & 0.04 & 0.05 \\
\hline & $(-1.09)$ & $(-0.92)$ & $(3.64)$ & $(3.67)$ & (3.69) & $(4.76)$ \\
\hline $\mathbf{R}^{2}$ & 0.91 & & 0.73 & & 0.90 & \\
\hline F-test & 40.29 & & 29.26 & & 47.23 & \\
\hline LM-test & & 5522.24 & & 2638.24 & & 11755.77 \\
\hline H-test & & 0.68 & & 0.33 & & 5.53 \\
\hline NOB & 301 & 301 & 282 & 282 & 583 & 583 \\
\hline NOC & 60 & 60 & 24 & 24 & 84 & 84 \\
\hline
\end{tabular}

Panel 2: The effect of government spending

\begin{tabular}{|c|c|c|c|c|c|c|}
\hline \multirow{2}{*}{$\begin{array}{r}\text { Sample } \\
\text { Model }\end{array}$} & \multicolumn{2}{|c|}{$\begin{array}{r}\text { Middle- and Low-income } \\
\text { Sample }\end{array}$} & \multicolumn{2}{|c|}{ High-Income Sample } & \multicolumn{2}{|c|}{ Complete Sample } \\
\hline & (1) FE & (2) $\mathrm{EC}$ & (3) $\mathrm{FE}$ & (4) EC & (5) $\mathrm{FE}$ & (6) EC \\
\hline \multirow[t]{2}{*}{ Constant } & -- & 44.39 & -- & 42.98 & -- & 44.55 \\
\hline & $(--)$ & $(21.62)$ & $(--)$ & (19.62) & $(--)$ & $(29.27)$ \\
\hline \multirow[t]{2}{*}{$\mathbf{Y}$} & 0.16 & -0.23 & -1.02 & -1.02 & -0.94 & -1.21 \\
\hline & $(0.23)$ & $(-0.36)$ & $(-3.99)$ & $(-4.07)$ & $(-3.78)$ & $(-5.32)$ \\
\hline \multirow[t]{2}{*}{$\mathbf{Y}^{2}$} & -0.09 & -0.06 & 0.05 & 0.05 & 0.04 & 0.05 \\
\hline & $(-1.36)$ & $(-1.03)$ & $(3.95)$ & $(4.00)$ & $(3.55)$ & (4.77) \\
\hline \multirow[t]{2}{*}{ G } & -0.17 & -0.11 & -0.34 & -0.38 & -0.18 & -0.12 \\
\hline & $(-2.36)$ & $(-1.67)$ & $(-2.85)$ & $(-3.60)$ & $(-3.26)$ & $(-2.40)$ \\
\hline $\mathbf{R}^{2}$ & 0.91 & & 0.74 & & 0.90 & \\
\hline F-test & 41.15 & & 23.97 & & 47.79 & \\
\hline LM-test & & 5520.76 & & 1808.76 & & 11162.64 \\
\hline H-test & & 3.68 & & 0.62 & & 9.82 \\
\hline NOB & 301 & 301 & 282 & 282 & 583 & 583 \\
\hline NOC & 60 & 60 & 24 & 24 & 84 & 84 \\
\hline
\end{tabular}


Table 6. Sensitivity Analysis of Regression (26) (Fixed-effects model)

Dependent variable: GINI

\begin{tabular}{|c|c|c|c|c|c|c|c|}
\hline & 1 (Base) & 2 & 3 & 4 & 5 & 6 & 7 \\
\hline \multicolumn{8}{|c|}{ The middle- and low-income sample } \\
\hline $\mathbf{Y}$ & $\begin{array}{r}-0.70 \\
(-2.40)\end{array}$ & $\begin{array}{r}-1.196 \\
(-3.289)\end{array}$ & $\begin{array}{r}-1.463 \\
(-3.729)\end{array}$ & $\begin{array}{r}-0.926 \\
(-2.395)\end{array}$ & $\begin{array}{r}-1.826 \\
(-4.445)\end{array}$ & $\begin{array}{r}-1.262 \\
(-3.129)\end{array}$ & $\begin{array}{r}-1.209 \\
(-3.110)\end{array}$ \\
\hline G & $\begin{array}{r}-0.16 \\
(-2.21)\end{array}$ & $\begin{array}{r}-0.16 \\
(-2.209)\end{array}$ & $\begin{array}{r}-0.086 \\
(-0.877)\end{array}$ & $\begin{array}{r}0.001 \\
(0.010)\end{array}$ & $\begin{array}{r}-0.062 \\
(-0.642)\end{array}$ & $\begin{array}{r}0.037 \\
(0.366)\end{array}$ & $\begin{array}{r}-0.08 \\
(-0.725)\end{array}$ \\
\hline PGRW & & $\begin{array}{r}-1.115 \\
(-1.416)\end{array}$ & $\begin{array}{r}-0.241 \\
(-0.276)\end{array}$ & $\begin{array}{r}-1.529 \\
(-1.694)\end{array}$ & & & \\
\hline OPEN & & $\begin{array}{r}0.054 \\
(2.486)\end{array}$ & & & $\begin{array}{r}0.06 \\
(2.241)\end{array}$ & $\begin{array}{r}0.069 \\
(2.835)\end{array}$ & \\
\hline FNDP & & & $\begin{array}{l}10.408 \\
(3.379)\end{array}$ & & $\begin{array}{r}7.709 \\
(2.425)\end{array}$ & & $\begin{array}{c}10.703 \\
(3.452)\end{array}$ \\
\hline TOTSK & & & & $\begin{array}{r}-0.109 \\
(-0.047) \\
\end{array}$ & & $\begin{array}{r}-0.461 \\
(-0.208) \\
\end{array}$ & $\begin{array}{r}-0.643 \\
(-0.287) \\
\end{array}$ \\
\hline NOB & 301 & 285 & 252 & 247 & 256 & 259 & 240 \\
\hline $\mathbf{R}^{2}$ & 0.905 & 0.905 & 0.91 & 0.914 & 0.917 & 0.926 & 0.921 \\
\hline F-test & 42.05 & 26.122 & 26.487 & 26.425 & 39.751 & 44.035 & 39.156 \\
\hline \multicolumn{8}{|c|}{ The high-income sample } \\
\hline $\mathbf{Y}$ & $\begin{array}{r}-0.04 \\
(-0.64)\end{array}$ & $\begin{array}{r}-0.01 \\
(-0.119)\end{array}$ & $\begin{array}{r}-0.169 \\
(-1.806)\end{array}$ & $\begin{array}{r}-0.028 \\
(-0.290)\end{array}$ & $\begin{array}{r}-0.14 \\
(-1.569)\end{array}$ & $\begin{array}{r}-0.014 \\
(-0.142)\end{array}$ & $\begin{array}{r}-0.185 \\
(-1.797)\end{array}$ \\
\hline G & $\begin{array}{r}-0.30 \\
(-2.41)\end{array}$ & $\begin{array}{r}-0.351 \\
(-2.690)\end{array}$ & $\begin{array}{r}-0.194 \\
(-1.330)\end{array}$ & $\begin{array}{r}-0.434 \\
(-3.017)\end{array}$ & $\begin{array}{r}-0.233 \\
(-1.640)\end{array}$ & $\begin{array}{r}-0.437 \\
(-3.045)\end{array}$ & $\begin{array}{r}-0.226 \\
(-1.506)\end{array}$ \\
\hline PGRW & & $\begin{array}{r}-0.416 \\
(-0.773)\end{array}$ & $\begin{array}{r}0.659 \\
(1.113)\end{array}$ & $\begin{array}{r}0.078 \\
(0.147)\end{array}$ & & & \\
\hline OPEN & & $\begin{array}{r}-0.029 \\
(-2.110)\end{array}$ & & & $\begin{array}{r}-0.037 \\
(-2.723)\end{array}$ & $\begin{array}{r}-0.007 \\
(-0.518)\end{array}$ & \\
\hline FNDP & & & $\begin{array}{r}3.152 \\
(2.397)\end{array}$ & & $\begin{array}{r}3.108 \\
(2.484)\end{array}$ & & $\begin{array}{r}3.531 \\
(2.910)\end{array}$ \\
\hline TOTSK & & & & $\begin{array}{r}0.362 \\
(0.189) \\
\end{array}$ & & $\begin{array}{r}0.137 \\
(0.070) \\
\end{array}$ & $\begin{array}{r}1.254 \\
(0.674) \\
\end{array}$ \\
\hline NOB & 282 & 281 & 255 & 236 & 255 & 236 & 224 \\
\hline $\mathbf{R}^{2}$ & 0.72 & 0.725 & 0.72 & 0.744 & 0.728 & 0.745 & 0.751 \\
\hline F-test & 22.18 & 20.793 & 20.724 & 20.593 & 20.52 & 18.632 & 21.667 \\
\hline \multicolumn{8}{|c|}{ The complete sample } \\
\hline $\mathbf{Y}$ & $\begin{array}{r}-0.09 \\
(-1.28)\end{array}$ & $\begin{array}{r}-0.127 \\
(-1.371)\end{array}$ & $\begin{array}{r}-0.327 \\
(-3.094)\end{array}$ & $\begin{array}{r}-0.084 \\
(-0.766)\end{array}$ & $\begin{array}{r}-0.333 \\
(-3.211)\end{array}$ & $\begin{array}{r}-0.09 \\
(-0.815)\end{array}$ & $\begin{array}{r}-0.335 \\
(-2.747)\end{array}$ \\
\hline G & $\begin{array}{r}-0.19 \\
(-3.40)\end{array}$ & $\begin{array}{r}-0.19 \\
(-3.230)\end{array}$ & $\begin{array}{r}-0.061 \\
(-0.817)\end{array}$ & $\begin{array}{r}-0.075 \\
(-0.933)\end{array}$ & $\begin{array}{r}-0.073 \\
(-0.994)\end{array}$ & $\begin{array}{r}-0.068 \\
(-0.856)\end{array}$ & $\begin{array}{r}-0.053 \\
(-0.652)\end{array}$ \\
\hline PGRW & & $\begin{array}{r}-0.35 \\
(-0.752)\end{array}$ & $\begin{array}{r}0.366 \\
(0.706)\end{array}$ & $\begin{array}{r}-0.519 \\
(-1.022)\end{array}$ & & & \\
\hline OPEN & & $\begin{array}{r}0.001 \\
(0.070)\end{array}$ & & & $\begin{array}{r}-0.008 \\
(-0.628)\end{array}$ & $\begin{array}{r}0.014 \\
(1.113)\end{array}$ & \\
\hline FNDP & & & $\begin{array}{r}5.097 \\
(3.977)\end{array}$ & & $\begin{array}{r}4.994 \\
(3.949)\end{array}$ & & $\begin{array}{r}5.695 \\
(4.514)\end{array}$ \\
\hline TOTSK & & & & $\begin{array}{r}0.192 \\
(0.126)\end{array}$ & & $\begin{array}{r}0.327 \\
(0.217)\end{array}$ & $\begin{array}{r}0.422 \\
(0.285)\end{array}$ \\
\hline NOB & 583 & 566 & 507 & 483 & 511 & 495 & 464 \\
\hline $\mathbf{R}^{2}$ & 0.89 & 0.898 & 0.907 & 0.911 & 0.909 & 0.915 & 0.92 \\
\hline F-test & 47.06 & 33.927 & 34.442 & 34.37 & 44.694 & 48.221 & 47.349 \\
\hline
\end{tabular}


Table 7. Sensitivity Analysis of Regressions (29) and (30) (Fixed-effects model)

Dependent variable: GINI

\begin{tabular}{|c|c|c|c|c|c|c|c|c|c|c|c|}
\hline & 1 (Base) & 2 & 3 & 4 & 5 & 6 & 7 & 8 & 9 & 10 & 11 \\
\hline \multicolumn{12}{|c|}{ The middle- and low-income sample } \\
\hline \multirow[t]{2}{*}{$\mathbf{Y}$} & -0.091 & -1.226 & -0.193 & 0.238 & -0.464 & -0.96 & -0.315 & 1.003 & -1.27 & 0.133 & 0.239 \\
\hline & $(-0.132)$ & $(-1.123)$ & $(-0.173)$ & $(0.230)$ & $(-0.443)$ & $(-1.016)$ & $(-0.317)$ & (1.031) & $(-1.276)$ & $(0.134)$ & $(0.254)$ \\
\hline \multirow[t]{2}{*}{$\mathbf{Y}^{2}$} & -0.072 & -0.055 & -0.113 & -0.138 & -0.098 & -0.021 & -0.11 & -0.187 & -0.052 & -0.129 & -0.14 \\
\hline & $(-1.092)$ & $(-0.597)$ & $(-1.226)$ & $(-1.541)$ & $(-1.124)$ & $(-0.272)$ & $(-1.258)$ & $(-2.157)$ & $(-0.614)$ & $(-1.529)$ & $(-1.686)$ \\
\hline \multirow[t]{2}{*}{$\mathbf{G}$} & & & & & & -0.162 & -0.083 & 0 & -0.065 & 0.022 & -0.072 \\
\hline & & & & & & $(-2.220)$ & $(-0.841)$ & $(0.002)$ & $(-0.669)$ & $(0.218)$ & $(-0.651)$ \\
\hline \multirow[t]{2}{*}{ PGRW } & & 0.192 & -0.823 & -0.115 & & -1.061 & 0.189 & -0.723 & & & \\
\hline & & $(0.208)$ & $(-0.865)$ & $(-0.117)$ & & $(-1.303)$ & $(0.202)$ & $(-0.746)$ & & & \\
\hline \multirow[t]{2}{*}{ OPEN } & & 0.057 & 0.058 & & 0.046 & 0.051 & & & 0.054 & 0.053 & \\
\hline & & (2.018) & (2.103) & & (1.596) & $(2.085)$ & & & (1.916) & (1.973) & \\
\hline \multirow[t]{2}{*}{ FNDP } & & 6.885 & & 8.471 & 7.008 & & 9.107 & & 7.194 & & 8.824 \\
\hline & & (2.119) & & $(2.634)$ & $(2.161)$ & & (2.807) & & (2.185) & & (2.691) \\
\hline \multirow[t]{2}{*}{ TOTSK } & & & -0.563 & -0.382 & -0.844 & & & -0.039 & & -0.448 & -0.676 \\
\hline & & & $(-0.252)$ & $(-0.172)$ & $(-0.383)$ & & & $(-0.017)$ & & $(-0.203)$ & $(-0.303)$ \\
\hline NOB & 301 & 252 & 247 & 236 & 240 & 285 & 252 & 247 & 256 & 259 & 240 \\
\hline $\mathbf{R}^{2}$ & 0.911 & 0.913 & 0.918 & 0.918 & 0.923 & 0.905 & 0.911 & 0.916 & 0.917 & 0.927 & 0.922 \\
\hline \multirow[t]{2}{*}{ F-test } & 40.289 & 22.726 & 24.093 & 23.604 & 39.24 & 23.055 & 22.575 & 23.76 & 38.234 & 43.695 & 38.346 \\
\hline & & & & The hi & h-inco & e sam & & & & & \\
\hline \multirow[t]{2}{*}{$\mathbf{Y}$} & -0.949 & -1.614 & -0.779 & -2.027 & -1.969 & -1.089 & -1.718 & -1.015 & -1.525 & -0.895 & -1.884 \\
\hline & $(-3.674)$ & $(-4.432)$ & $(-2.141)$ & $(-4.578)$ & $(-4.663)$ & $(-3.667)$ & $(-4.839)$ & $(-2.905)$ & $(-4.313)$ & $(-2.666)$ & $(-4.795)$ \\
\hline \multirow[t]{2}{*}{$\mathbf{Y}^{2}$} & 0.043 & 0.062 & 0.037 & 0.076 & 0.074 & 0.047 & 0.065 & 0.043 & 0.058 & 0.039 & 0.07 \\
\hline & (3.639) & (4.195) & $(2.440)$ & (4.409) & $(4.460)$ & (3.778) & $(4.509)$ & $(2.937)$ & $(4.039)$ & $(2.738)$ & $(4.466)$ \\
\hline \multirow[t]{2}{*}{ G } & & & & & & -0.403 & -0.142 & -0.486 & -0.154 & -0.472 & -0.162 \\
\hline & & & & & & $(-3.155)$ & $(-1.011)$ & $(-3.414)$ & $(-1.113)$ & $(-3.325)$ & $(-1.121)$ \\
\hline \multirow[t]{2}{*}{ PGRW } & & -0.177 & -0.323 & -0.337 & & -0.868 & -0.035 & -0.548 & & & \\
\hline & & $(-0.293)$ & $(-0.536)$ & $(-0.557)$ & & $(-1.614)$ & $(-0.060)$ & $(-0.968)$ & & & \\
\hline \multirow[t]{2}{*}{ OPEN } & & -0.021 & 0.002 & & 0.005 & -0.018 & & & -0.021 & 0.004 & \\
\hline & & $(-1.482)$ & $(0.118)$ & & $(0.361)$ & $(-1.314)$ & & & $(-1.526)$ & $(0.302)$ & \\
\hline \multirow[t]{2}{*}{ FNDP } & & 6.504 & & 7.549 & 7.564 & & 6.023 & & 5.921 & & 6.947 \\
\hline & & (5.039) & & (5.810) & (5.790) & & (4.259) & & $(4.238)$ & & (5.003) \\
\hline \multirow[t]{2}{*}{ TOTSK } & & & -0.085 & 0.49 & 0.74 & & & -0.4 & & -0.155 & 0.54 \\
\hline & & & $(-0.042)$ & $(0.272)$ & $(0.405)$ & & & $(-0.211)$ & & $(-0.080)$ & $(0.303)$ \\
\hline NOB & 282 & 255 & 236 & 224 & 224 & 281 & 255 & 236 & 255 & 236 & 224 \\
\hline $\mathbf{R}^{2}$ & 0.728 & 0.745 & 0.741 & 0.772 & 0.772 & 0.74 & 0.743 & 0.755 & 0.746 & 0.754 & 0.774 \\
\hline F-test & 29.26 & 25.095 & 22.523 & 27.432 & 25.733 & 22.127 & 23.329 & 21.469 & 22.574 & 19.476 & 24.647 \\
\hline & & & & The & omplet & sampl & & & & & \\
\hline $\bar{Y}$ & -0.982 & -1.947 & -1.163 & -1.841 & -1.985 & -1.226 & -1.848 & -0.953 & -1.914 & -0.99 & -1.703 \\
\hline & $(-3.926)$ & $(-5.402)$ & $(-3.181)$ & $(-4.652)$ & $(-4.994)$ & $(-4.086)$ & $(-5.404)$ & $(-2.779)$ & $(-5.510)$ & $(-2.895)$ & $(-4.638)$ \\
\hline $\mathbf{Y}^{2}$ & 0.043 & 0.071 & 0.048 & 0.066 & 0.072 & 0.05 & 0.068 & 0.04 & 0.07 & 0.042 & 0.061 \\
\hline & $(3.686)$ & $(4.736)$ & (3.048) & $(4.045)$ & (4.358) & $(3.845)$ & $(4.665)$ & (2.673) & $(4.758)$ & $(2.778)$ & (3.942) \\
\hline G & & & & & & -0.186 & -0.063 & -0.087 & -0.061 & -0.066 & -0.058 \\
\hline & & & & & & $(-3.214)$ & $(-0.866)$ & $(-1.084)$ & $(-0.851)$ & $(-0.838)$ & $(-0.736)$ \\
\hline PGRW & & -0.125 & -0.753 & -0.583 & & -0.757 & -0.273 & -0.99 & & & \\
\hline & & $(-0.237)$ & $(-1.404)$ & $(-1.051)$ & & $(-1.607)$ & $(-0.521)$ & $(-1.853)$ & & & \\
\hline OPEN & & 0.013 & 0.026 & & 0.026 & 0.015 & & & 0.013 & 0.027 & \\
\hline & & $(0.935)$ & $(1.861)$ & & (1.893) & (1.183) & & & $(0.951)$ & $(2.032)$ & \\
\hline FNDP & & 7.511 & & 7.905 & 7.928 & & 7.473 & & 7.449 & & 7.919 \\
\hline & & (5.569) & & (5.787) & $(5.850)$ & & $(5.531)$ & & $(5.570)$ & & (5.819) \\
\hline TOTSK & & & 0.144 & 0.047 & 0.237 & & & -0.215 & & 0.107 & 0.036 \\
\hline & & & $(0.096)$ & $(0.032)$ & $(0.164)$ & & & $(-0.142)$ & & $(0.072)$ & $(0.025)$ \\
\hline NOB & 583 & 507 & 483 & 460 & 464 & 566 & 507 & 483 & 511 & 495 & 464 \\
\hline $\mathbf{R}^{2}$ & 0.903 & 0.912 & 0.913 & 0.922 & 0.924 & 0.901 & 0.912 & 0.912 & 0.914 & 0.917 & 0.923 \\
\hline F-test & 47.227 & 35.184 & 34.206 & 36.577 & 49.217 & 34.894 & 35.609 & 34.315 & 46.902 & 48.347 & 49.172 \\
\hline
\end{tabular}


Table 8. Data Appendix

\begin{tabular}{|c|c|}
\hline Variables & Sources \\
\hline (1) Gini coefficients (GINI) & Deininger, Squire and Zhang, (1995), World Bank. \\
\hline (2) Real per capita income (Y) & Summers and Heston (1994). \\
\hline (3) Government spending (G) & Summers and Heston (1994). \\
\hline (4) Openness (OPEN) & $\begin{array}{l}\text { (Export + Import) / GDP, Summers and Heston } \\
\text { (1994). }\end{array}$ \\
\hline (5) Financial development (FNDP) & M2 / GDP, IFS, IMF. \\
\hline (6) Terms of trade shocks (TOTSK) & $\begin{array}{l}\Delta \ln (\text { Export price) }-\Delta \ln (\text { Import price), IFS (IMF) and } \\
\text { World Bank Trade Statistics. }\end{array}$ \\
\hline (7) Population growth (PGRW) & World Bank Social Indicators. \\
\hline
\end{tabular}

